\title{
Short-term and medium-term health effects of 9/11
}

\author{
Sharon E Perlman, Stephen Friedman, Sandro Galea, Hemanth P Nair, Monika Erős-Sarnyai, Steven D Stellman, Jeffrey Hon, Carolyn M Greene
}

The New York City terrorist attacks on Sept 11, 2001 (9/11), killed nearly 2800 people and thousands more had subsequent health problems. In this Review of health effects in the short and medium terms, strong evidence is provided for associations between experiencing or witnessing events related to $9 / 11$ and post-traumatic stress disorder and respiratory illness, with a correlation between prolonged, intense exposure and increased overall illness and disability. Rescue and recovery workers, especially those who arrived early at the World Trade Center site or worked for longer periods, were more likely to develop respiratory illness than were other exposed groups. Risk factors for post-traumatic stress disorder included proximity to the site on 9/11, living or working in lower Manhattan, rescue or recovery work at the World Trade Center site, event-related loss of spouse, and low social support. Investigators note associations between 9/11 exposures and additional disorders, such as depression and substance use; however, for some health problems association with exposures related to $9 / 11$ is unclear.

\section{Introduction}

The Sept 11, 2001 (9/11), terrorist attacks exposed many people to a wide range of horrific events: they saw planes crashing into buildings, people falling from buildings, and the collapse of the World Trade Center (WTC) towers; they were trapped in the dust cloud; and they witnessed injury and death. ${ }^{1}$ Many lost relatives, friends, and colleagues. Rescue and recovery workers found body remains and personal effects of the deceased. Many people experienced stress, fear, and uncertainty. In the weeks after 9/11, public areas in New York City were covered with pictures of missing people, many of whom had died in the attacks. Furthermore, thousands of people were temporarily or permanently unable to return to their homes, workplaces, or schools.

Additionally, the collapse of the WTC towers exposed many to substances that have been shown to adversely affect health. Routine environmental monitoring equipment in lower Manhattan was damaged and destroyed in the aftermath of the attacks, which made it difficult to quantify exposure to the massive dust cloud generated by the collapsing towers and potentially to toxic substances that permeated the clean-up site, residences, and workplaces in the area. Sampling for asbestos, organochlorine compounds, volatile organic compounds, and polycyclic aromatic hydrocarbons began between Sept 14 and Sept 21, 2001.-.$^{2-5}$ The dust and debris contained powdered concrete, gypsum, glass fibres, chrysotile asbestos, polycyclic aromatic hydrocarbons, steel, and several metals such as lead, aluminum, antimony, chromium, molybdenum, and barium. ${ }^{6,7}$ The dust was highly alkaline ( $\mathrm{pH}$ up to 11 ) and had high concentrations of particulate matter capable of causing respiratory irritation and damage. ${ }^{6}$ The destroyed buildings also contained electrical cable coated in polyvinyl chloride, some of which was incinerated during and after the collapse of the towers, which caused the release of dioxins and other chlorinated organic compounds into the atmosphere. ${ }^{6}$

Studies of the health effects of $9 / 11$ have generally focused on three distinct populations: directly exposed groups (rescue and recovery workers, volunteers, lower
Manhattan residents, people who worked in the lower Manhattan area, school staff and students, and passers-by on 9/11; table); those indirectly exposed in New York City (eg, who were not near the WTC site on $9 / 11$ or during the weeks afterwards, and who did not lose a loved one or a job as a result of the attacks); or those indirectly exposed throughout the USA and internationally.

This Review investigates the health effects of the 9/11 terrorist attacks in the short and medium terms to establish what has been learned, and to identify areas in which further research is needed.

\section{Mental health}

More than 150 studies have documented the mental health effects of $9 / 11$. These reports can be divided into two groups: those that documented stress reactions and psychopathology nationwide, and those that focused on psychopathology in the New York City metropolitan area. Most WTC investigators used screening instruments to assess post-traumatic stress disorder (PTSD) such as the PTSD checklist. ${ }^{37}$ High scores on the checklist are often referred to as probable PTSD because these instruments are not diagnostic for the disorder. Other studies assessed post-traumatic stress symptoms, indicating that

\section{Search strategy and selection criteria}

We searched PubMed for reports in English between Sept 11, 2001, and February, 2011, with the search terms "September 11 Terrorist Attacks", "World Trade Center", "WTC", and "September 11, 2001". To ensure comprehensiveness, we compared the results of our search to relevant reviews. In view of the amount of work on this topic, we could not comprehensively include all peer-reviewed reports. Therefore, in this Review we summarise the information from the largest and most representative studies, in addition to studies that cover a topic not adequately addressed in previous papers. We assessed which papers merited inclusion on the basis of study methods used. The webappendix contains more information about each study discussed.
Lancet 2011; 378: 925-34 Division of Epidemiology (SE Perlman MPH, S Friedman MD, H P Nair PhD, Prof S D Stellman PhD, J Hon BA, (M Greene MD) and Division of Mental Hygiene

(M Erős-Sarnyai MD), New York City Department of Health and Mental Hygiene, Queens, NY,

USA; and Department of Epidemiology, Mailman School of Public Health, Columbia University, New York, NY, USA (Prof S Galea MD,

Prof S D Stellman)

Correspondence to:

Ms Sharon E Perlman, Division of Epidemiology, New York City Department of Health and Mental Hygiene, 42-09 28th Street, CN \#6, Queens, NY 11101, USA sperlma1@health.nyc.gov 


\begin{tabular}{|c|c|c|c|}
\hline & Groups studied & Size (on Dec 31, 2010)* & Other distinguishing characteristics \\
\hline $\begin{array}{l}\text { Fire Department of } \\
\text { New York }{ }^{8-15}\end{array}$ & $\begin{array}{l}\text { Nearly all firefighters and emergency } \\
\text { medical service workers who responded } \\
\text { to WTC disaster }\end{array}$ & $\begin{array}{l}15415 \text { screened so far; } \\
5686 \text { treated in past } \\
12 \text { months }\end{array}$ & $\begin{array}{l}\text { Established in 2001; employer-based medical programme with physical examinations } \\
\text { done about every } 18 \text { months; has medical records before } 9 / 11 \text {; provides screening, } \\
\text { monitoring, and treatment }\end{array}$ \\
\hline $\begin{array}{l}\text { New York and New Jersey } \\
\text { WTC Clinical Consortium } \\
\text { W6-24 }^{1}\end{array}$ & $\begin{array}{l}\text { Law enforcement and other responders, } \\
\text { sanitation and construction workers, and } \\
\text { volunteers }\end{array}$ & $\begin{array}{l}29572 \text { screened so far; } \\
8411 \text { treated in past } \\
12 \text { months }\end{array}$ & $\begin{array}{l}\text { Established in 2002; provides screening, monitoring, and treatment through } \\
\text { environmental and occupational health clinics to an ethnically and socioeconomically } \\
\text { diverse population; up to } 19 \% \text { of patients do not have insurance yearly } \dagger\end{array}$ \\
\hline $\begin{array}{l}\text { WTC Environmental } \\
\text { Health Center }{ }^{25.26}\end{array}$ & $\begin{array}{l}\text { Lower Manhattan area clean-up workers, } \\
\text { office workers, residents, students, school } \\
\text { staff, and passers-by }\end{array}$ & $\begin{array}{l}5130 \text { examined so far; } \\
2520 \text { treated in past } \\
12 \text { months }\end{array}$ & $\begin{array}{l}\text { Began in } 2005 \text { as privately funded programme at an asthma clinic in a New York City } \\
\text { public hospital; monitors and treats but does not screen (patients are only accepted if } \\
\text { symptomatic); includes children; up to } 50 \% \text { of patients do not have insurance yearly }{ }^{\prime}\end{array}$ \\
\hline WTC Health Registry ${ }^{1,27-34}$ & $\begin{array}{l}\text { Rescue and recovery workers, lower } \\
\text { Manhattan residents, area workers, } \\
\text { students, and passers-by }\end{array}$ & $\begin{array}{l}71437 \text { responded to first } \\
\text { survey; } 68 \% \text { adults } \\
\text { responded to second survey }\end{array}$ & $\begin{array}{l}\text { Closed cohort recruited in } 2003-04 ; 30 \% \text { recruited through lists provided by entities } \\
\text { such as employers and government agencies, and the remaining } 70 \% \text { self-enrolled; } \\
\text { surveys done } 2-3 \text { years and } 5-6 \text { years after } 9 / 11 \text {; includes children }\end{array}$ \\
\hline
\end{tabular}

WTC=World Trade Center. 9/11=Sept 11, 2001. *Number of people screened and treated are from the National Institute for Occupational Safety and Health. ${ }^{35}+$ Data from WTC Medical Working Group of New York City. ${ }^{36}$

Table: WTC populations being studied with funding from the National Institute for Occupational Safety and Health

respondents endorsed symptoms of stress but did not meet PTSD criteria.

\section{Stress reactions in the USA}

Measurements taken 3-5 days after 9/11 suggested that $44 \%$ of the adult US population experienced substantial stress. ${ }^{38}$ Findings from subsequent national studies also showed that individuals across the country experienced fear and insecurity, and had increased rates of posttraumatic stress symptoms 2 months later. ${ }^{39,40}$ Research into the potential causes of these symptoms among people with no direct exposure to the $9 / 11$ attacks, or to other disasters, could be beneficial in view of the broad reach of mass media compared with direct exposure after a disaster. ${ }^{41}$ Risk factors associated with posttraumatic stress symptoms up to 4 years after $9 / 11$ included pre-event psychopathology, ${ }^{42}$ female sex, ${ }^{40,43}$ recent immigration to the USA, ${ }^{43}$ and increased hours of viewing event-related media coverage. ${ }^{40,43}$ Overall, individuals who lived outside the New York City metropolitan area were significantly less likely to have probable PTSD than were those inside the area 2 months after $9 / 11$ (4\% vs $11 \%, \mathrm{p}=0 \cdot 007) .{ }^{40}$ A $2004-05$ survey $^{44}$ of nearly 35000 US adults showed that those who had indirect experience of 9/11—eg, witnessed the attack on television-had the lowest risk of PTSD (1\%) of 32 traumatic events listed.

\section{PTSD and depression in New York City}

Studies done in the New York City metropolitan area focused on psychopathology, particularly PTSD and depression. Several studies based on a series of crosssectional surveys ${ }^{45,46}$ and subsequent longitudinal work ${ }^{47}$ led by New York Academy of Medicine researchers showed that 1-2 months after 9/11, the prevalence of PTSD in 988 residents of Manhattan south of 110th Street was $7 \cdot 5 \%$, and that for depression was $9.7 \%$. Peri-event panic attacks, loss of possessions, and job loss were risk factors for the development of PTSD, and low social support was a risk factor for depression. ${ }^{45}$ Prevalence of both PTSD and depression had decreased by 6 months after the terrorist attacks. ${ }^{46}$

Other investigations have focused on rescue and recovery workers, lower Manhattan residents, students, workers, and passers-by on the day of the attack. The prevalence of PTSD and depression documented was, as expected, higher in all these directly exposed groups than in the general population, and studies describe chronic and delayed-onset PTSD. ${ }^{8,27}$ Investigators who used data from the WTC Health Registry ${ }^{48}$ showed that the prevalence of PTSD 2-3 years after 9/11 was $12.4 \%$ in rescue and recovery workers and volunteers, with a range from $6 \cdot 2 \%$ for police to $21 \cdot 2 \%$ for unaffiliated volunteers. ${ }^{28}$ In other studies, PTSD after $9 / 11$ in firefighters and other rescue and recovery workers has also been associated with functional impairment and disability. ${ }^{8,16}$ Comorbidity is common: in recovery workers with probable PTSD, $12.7 \%$ also met criteria for panic disorder or depression. ${ }^{16}$ An earlier start date, longer duration of time worked at the WTC site, and performance of tasks not part of a person's occupation were significant risk factors for probable PTSD. ${ }^{28}$ Of 3271 workers who evacuated the WTC towers, $15 \%$ had probable PTSD 2-3 years after 9/11. An increased risk of the disorder was associated with presence on a higher floor in the WTC towers, late evacuation, exposure to the dust cloud, witnessing horrors, injury, and employment by a firm that sustained fatalities. ${ }^{29}$

In people enrolled in the WTC Health Registry who did not report a PTSD diagnosis before 9/11, the prevalence of the disorder was higher 5-6 years after the attacks $(19 \%)$ than after $2-3$ years $(14 \%) .{ }^{27}$ Late-onset PTSD (a report of symptoms consistent with PTSD in the 2006-07 survey, but not in the 2003-04 survey) had developed in $10 \% .{ }^{27}$ The prevalence of chronic PTSD (ie, a positive screen at both timepoints) was highest in rescue and recovery workers, whereas people who worked in lower Manhattan were most likely to have PTSD that had resolved by the time of the second survey (figure 1). Eventrelated loss of spouse or job, and low social support were factors associated with probable PTSD at the time of the 
second survey. ${ }^{27}$ Researchers have reported an association between trauma before or after the $9 / 11$ attacks and more severe and persistent PTSD after 9/11 in lower Manhattan residents and workers at the WTC site..$^{1727,49}$

These WTC studies described have some limitations. First, differences in the measurement of symptoms and in recruitment methods might have affected prevalence estimates and restrict comparisons. Two-thirds of the WTC Health Registry participants heard about the Registry through the media and advertising and self-enrolled, and a third were identified and recruited through lists of people thought to be present in the area. ${ }^{30}$ Registry prevalences of mental health conditions might therefore be overestimates, driven by self-selection and inclusion into the study by individuals who are more sick or more likely to report symptoms. Medical monitoring programmes could be subject to similar self-selection. Second, most studies used screening measures that are proxies for diagnosed disease and have imperfect sensitivity and specificity. ${ }^{50}$ Third, most of the included investigations have limited information about pre-event psychopathology, so whether PTSD or depression documented after the attacks was new, or a reactivation of previous illness, is unclear. A large proportion of documented mental health problems after mass traumatic events is known to occur in people who already had the disorders. ${ }^{51}$

\section{Substance use}

A small amount of work into substance use shows an increased use of alcohol, ${ }^{16,52-55}$ tobacco, and marijuana in New York City after 9/11. ${ }^{52}$ High-level or direct exposure to the attacks has been shown to be an associated factor for increased alcohol use in both adults and adolescents, but rates of smoking rose independently of exposure level. ${ }^{53,54}$ In adults, PTSD was associated with increased cigarette smoking after 9/11, and depression with increases in both smoking and alcohol use. ${ }^{55}$ Similarly, rescue and recovery workers with comorbid probable PTSD, depression, and panic disorder were more likely to report higher alcohol use and emotional disability than were others. ${ }^{16}$ Substance use in adolescents was linked to knowing someone who died in the attacks and self-report of a parent with decreased functioning. ${ }^{56}$

\section{Suicide}

Although some studies have shown no significant change in the risk of suicide at the population level in the month after $9 / 11$ compared with previous years, ${ }^{57,58}$ others note a significant decrease in suicide both in the New York City area $^{59}$ and internationally. ${ }^{60}$ Greater communal support and unity in the aftermath of the $9 / 11$ attacks might have decreased the risk of suicide. ${ }^{59,60}$

\section{Mental health of children in New York City}

The mental health effects of $9 / 11$ have not been as well studied in children as in adults. In a sample of 8236 New York City students aged 9-21 years taken

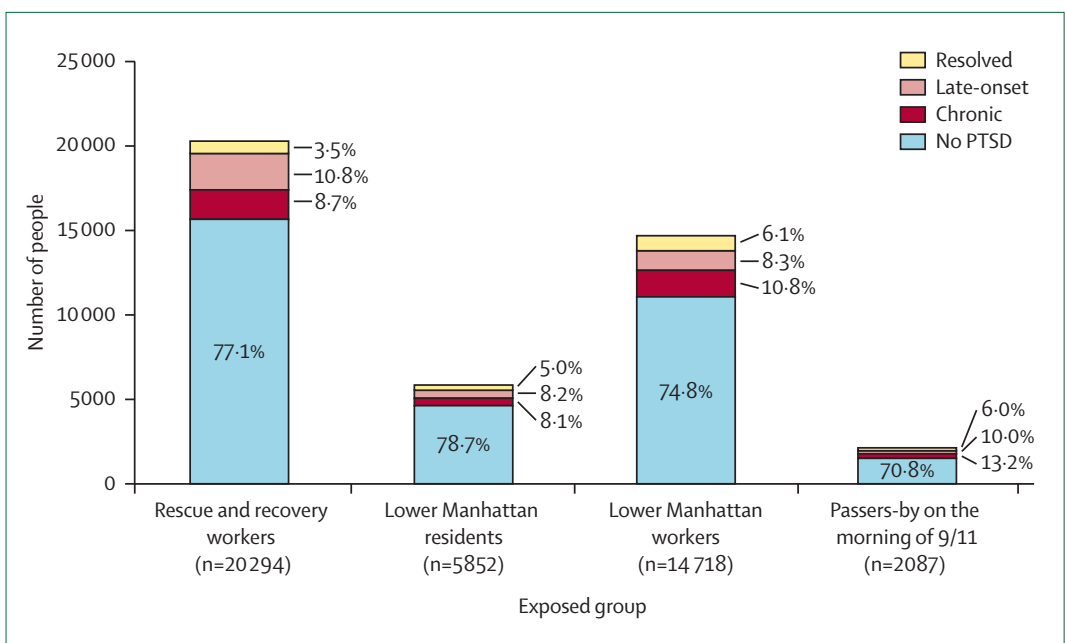

Figure 1: Course of PTSD symptoms in exposed groups

Data are from Brackbill and colleagues. ${ }^{27}$ Analysis is restricted to individuals enrolled in the World Trade Center Health Registry who did not have a diagnosis of PTSD before 9/11. PTSD=post-traumatic stress disorder. No PTSD=negative screen for PTSD symptoms at both the baseline (2003-04) and follow-up (2006-07) surveys. Chronic=positive screen for probable PTSD (as assessed by a PTSD checklist score $\geq 44$ ) at both timepoints. Late-onset=positive screen at follow-up survey only. Resolved=positive screen at baseline survey only. 9/11= Sept 11, 2001.

6 months after $9 / 11,29 \%$ of children had at least one of six anxiety or depressive disorders assessed. ${ }^{61}$ The most prevalent were probable agoraphobia $(15 \%)$, separation anxiety $(12 \%)$, and PTSD (11\%). ${ }^{61}$ Higher rates were associated with greater exposure (a composite variable including proximity to the attack, injury, dust cloud exposure, and death or injury of family member), female sex, a younger age (9-10 years), and a history of previous trauma. ${ }^{61}$ The severity of children's reactions has been positively correlated with parental distress (parental post-traumatic stress and crying in front of the child) and with the number of graphic images seen on television. ${ }^{62}$ In New York City, children who had probable peri-event panic attacks were more likely to have probable PTSD 6-9 months later than were those who had not had peri-event panic attacks related to 9/11. ${ }^{63}$ A study of 116 children aged 5 years and younger in lower Manhattan ${ }^{64}$ showed that children with a history of other trauma were at a greater risk of anxiety and depression symptoms, and sleep problems 2-4 years after the attacks.

\section{Physical health}

\section{Respiratory health of adults}

Respiratory illnesses in people exposed to the WTC attack began on a large scale immediately after $9 / 11$. Despite improvement in most individuals since $9 / 11$, thousands continue to have long-term symptomatic and functional problems. Individuals with more intense, prolonged WTC exposures generally experienced more severe and persistent respiratory illness. Clinician-reported or selfreported diagnoses of upper-respiratory symptoms (such as nasal or sinus congestion, sore throat, and laryngitis) and, at lower prevalence, lower-respiratory symptoms 


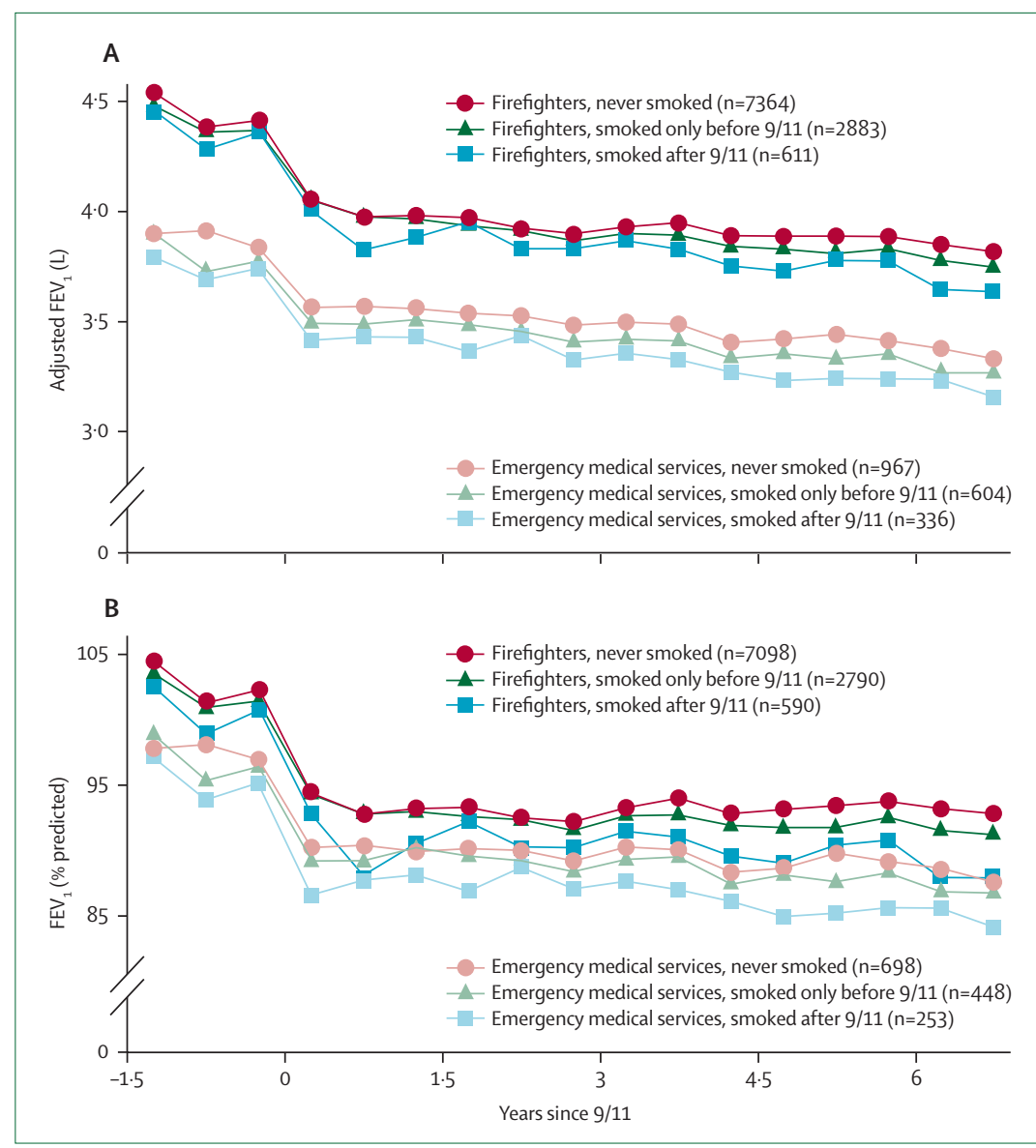

Figure 2: Lung function in firefighters and emergency medical services workers according to smoking status (A) Adjusted $\mathrm{FEV}_{1}$ over time. (B) $\mathrm{FEV}_{1}$ measurement compared with predicted values over time. $\mathrm{FEV}_{1}=$ forced expiratory volume in 1 s. 9/11=Sept 11, 2001. Reproduced from Aldrich and colleagues, ${ }^{12}$ by permission of the Massachusetts Medical Society. most, but reported rhinosinusitis remained at more than $40 \%$ by the fourth year. Lower-respiratory symptoms of dyspnoea ( $40 \%$ vs $3 \%$ ) and wheeze (34\% vs $1 \%$ ) were increased in the year after $9 / 11$ compared with before the attack. Dyspnoea and wheezing were reported more often in the second year and rates remained high through to the fourth year of follow-up. ${ }^{10}$ In firefighters, arrival time, months of working at the WTC site, presence of respiratory symptoms in the first year, current smoking, and older age on $9 / 11$ were significant predictors of lowerrespiratory symptoms 4 years after $9 / 11 .^{10}$

Pulmonary function data provide objective physiological evidence of abnormality and complement symptom reporting. Spirometry done a median of 3 months after 9/11 in 12079 New York City Fire Department responders showed an average decrease of $372 \mathrm{~mL}$ in forced expiratory volume in $1 \mathrm{~s}\left(\mathrm{FEV}_{1}\right)$ from their last pre-9/11 measurement, which is equal to the loss expected in 12 years of normal ageing. The proportion of those with $\mathrm{FEV}_{1}$ less than normal increased from $6 \cdot 8 \%$ before $9 / 11$ to $15 \cdot 3 \%$ afterwards. ${ }^{9} \mathrm{~A}$ higher rate of decline was correlated with the degree of exposure, as estimated by date of arrival at the WTC site.

After the substantial drop in the first year post-9/11, spirometry in firefighters and emergency medical service workers showed a stabilisation of function, with most having normal, albeit diminished $\mathrm{FEV}_{1}$ values compared with pre-disaster levels (figure 2). ${ }^{12}$ During the subsequent 6 years of follow-up, $\mathrm{FEV}_{1}$ adjusted for race, sex, height, and age on $9 / 11$ in firefighters who had never smoked decreased by $26 \mathrm{~mL}$ per year, and the average percentage of predicted $\mathrm{FEV}_{1}$ did not change. ${ }^{12}$ Smokers had a similar pattern but at a steeper rate of decline than did non-smokers (figure 2). Although an earlier arrival on $9 / 11$ predicted a decrease in adjusted $\mathrm{FEV}_{1}$ in the first year, it did not predict adjusted $\mathrm{FEV}_{1}$ at the conclusion of follow-up. This finding suggests that exposure predicted initial illness, but that individual host factors such as genomics or non-WTC exposures affected the long-term course. ${ }^{12,13}$

Similar symptom and lung-function findings have been reported in other responder groups (such as construction workers, sanitation workers, and volunteers). Of 9442 responders examined between 2002 and 2004 in the New York and New Jersey WTC Clinical Consortium treatment programme, $55 \%$ of those who were asymptomatic before the disaster and had worked during the year after the disaster reported upper-respiratory symptoms and $44 \%$ reported lower-respiratory symptoms. ${ }^{18}$ Of people with new or worsening symptoms, prevalence of respiratory disorders increased with exposure to the dust cloud and arrival on 9/11 versus arrival later in September onwards..$^{18}$ Of 25748 workers enrolled in the WTC Registry, rates of self-reported newly diagnosed asthma were highest in those who had arrived earliest and those exposed to the dust cloud; longer duration of work and no consistent use of mask or respirator were also predictive of asthma, independent of arrival time. ${ }^{31}$ Individuals who 
worked more than 90 days at the WTC site were $74 \%$ more likely to report newly diagnosed asthma, independent of arrival time, than were those who worked 1 week or less. ${ }^{31}$ Similarly, findings from a study of cleanup and recovery workers showed that longer duration of work at the WTC site was predictive of lower-respiratory symptoms. ${ }^{65}$ Although generally less exposed than many responders because they arrived later at the WTC site, New York State emergency responders with higher exposure to the aftermath of the disaster were more likely to self-report lower-respiratory symptoms, but not newly diagnosed asthma during the 2 years after $9 / 11$, than were non-exposed employees. ${ }^{66}$ Lower-respiratory symptoms persisted in some of these workers 5 years after $9 / 11 .^{67}$

Even in the absence of data from before $9 / 11$, spirometry has provided useful information for other responder populations. Abnormal spirometry was recorded in $29 \%$ of 240 police officers after $9 / 11,{ }^{68}$ and in $28 \%$ of 9442 other emergency and recovery personnel. ${ }^{18}$ Follow-up of 3160 of these responders from the New York and New Jersey WTC Clinical Consortium, between 2004 and 2007, showed a modest mean decrease in FEV of only $13 \mathrm{~mL}$ per year. At the follow-up study, $24 \%$ had abnormal spirometry. Consistency of longitudinal followup results in responders in the fire department and the consortium lends support to the conclusion that spirometry results stabilised after the initial decline.

Excess rates of upper-respiratory and lower-respiratory symptoms have also been documented in other populations. Predictors for respiratory symptoms in residents, area workers, and passers-by were exposure to the dust cloud, residential dust and damage, and not having evacuated homes. ${ }^{1,13,27}$ In 20996 adult WTC Health Registry enrollees in these groups surveyed 5-6 years after $9 / 11$, asthma diagnosed after $9 / 11$ was self-reported by $9 \%$ of passers-by, $8 \%$ of area workers, and $8 \%$ of lower Manhattan residents. ${ }^{27}$ As with responders, respiratory symptoms in other groups have been reported to persist for several years. For 1898 residents, local workers, and clean-up workers seen at the WTC Environmental Health Center from 2005 to 2008, dyspnoea on exertion (67\%) and cough $(46 \%)$ were the most reported symptoms, followed by nasal or sinus congestion (39\%), wheeze (27\%), and chest tightness (28\%). ${ }^{26}$ Additionally, as with responders, decreased forced vital capacity and airway hyper-reactivity on methacholine challenge accompanied persistent lower-respiratory symptoms in this group, whose members were similar in age to rescue and recovery populations but had a higher proportion of women. ${ }^{11}$

Despite the in-depth examination and follow-up of thousands of adults with new and worsening respiratory illness after 9/11, the pathophysiology of these disorders is incompletely understood. Primary spirometry findings along with isolated reports of acute eosinophilic pneumonia, ${ }^{14}$ granulomatous pneumonitis, ${ }^{69}$ and bronchiolitis obliterans, ${ }^{70}$ initially implicated interstitial processes as a disease explanation. However, air trapping and bronchial-wall thickening identified on CT, increased residual volume, airway hyper-reactivity, and improvement with bronchodilators in responders, residents, area workers, and clean-up workers ${ }^{13,26,71}$ suggested that airway obstruction in WTC respiratory disease pathogenesis is a possible explanation. A third factor, distal airway involvement, was implicated by increased airway resistance measurements in a group of WTC-exposed residents and workers with lower-respiratory symptoms and normal spirometry. ${ }^{72}$ Limitations of some 9/11-related mental health studies-such as self-selection bias, selfreport of symptoms and diagnoses, and inability to rule out pre-existing conditions or continuing exposures unrelated to 9/11—also apply to many studies reporting respiratory outcomes.

\section{Respiratory health of children}

Few studies have addressed the disaster's effects on children's respiratory health. ${ }^{32,73}$ Prevalence of age-specific diagnosed asthma before $9 / 11$ in children enrolled in the WTC Health Registry was similar to that in the 2003 Centers for Disease Control and Prevention's National Health Interview Survey, ${ }^{74}$ but the rates reported in the registry's 2003-04 survey ${ }^{32}$ were significantly higher: $18 \%$ of 2570 children versus $14 \%$ of about 1.8 million children in northeast USA. Asthma diagnosed after $9 / 11$ was reported in $6 \%$ of 3184 children enrolled in the WTC Health Registry (11\% of children aged $0-4$ years on $9 / 11$ ), and was significantly associated with Asian and Hispanic race or ethnicity and intense dust cloud exposure. ${ }^{32}$

\section{Injuries}

Hospital use was low after 9/11, indicating relatively few severe, acute injuries despite the scale of the disaster. An analysis of emergency room data from five New York City hospitals showed that 790 survivors with injuries sought care within $48 \mathrm{~h}$ of the attack, including 279 rescue workers, and $18 \%$ were admitted..$^{75}$ Inhalation and ocular injuries were most common. In a survey $2-3$ years after 9/11, 3672 adult survivors of collapsed and damaged buildings (excluding rescue workers) reported that they had been injured, with ocular injury most common (32\%). ${ }^{33}$ Event-related injury has also been reported to be a risk factor for probable PTSD. ${ }^{27,29}$

\section{Gastro-oesophageal reflux symptoms}

In cross-sectional studies of 10378 firefighters, $54 \%$ reported gastro-oesophageal reflux symptoms (GERS) 1 year after 9/11, and this proportion was the same 4 years later. ${ }^{10}$ Furthermore, of 554 WTC rescue and recovery workers in the New York and New Jersey Clinical Consortium, 30\% were reported to have GERS and problems in both the upper and lower respiratory systems. GERS was more prevalent in those who arrived at the WTC site within the first $48 \mathrm{~h}$ than in those who arrived later. ${ }^{20}$ In the WTC Health Registry, $24 \%$ of 8418 survivors of collapsed and damaged buildings (not 
including rescue and recovery workers) self-reported heartburn or indigestion 2-3 years after the event. ${ }^{33}$ GERS are common; a population-based study of 2200 adults in Minnesota reported that $20 \%$ of participants had heartburn or acid reflux at least once a week. ${ }^{7}$ Previous research had documented comorbidity of GERS with asthma, ${ }^{77,78}$ mental health disorders, ${ }^{79}$ and stress $^{80}$ — conditions that are associated with 9/11-related exposures. Other studies have reported coexisting sinus, lower-respiratory, and gastro-oesophageal symptoms in WTC responders..$^{10,21}$

\section{Sarcoidosis}

Rates of sarcoidosis, a multisystem granulomatous disease of possible environmental aetiology, have been examined in people exposed to the WTC disaster. The incidence of a sarcoid-like granulomatous pulmonary disease in firefighters increased in the first year after 9/11 compared with the average for the previous 15 years (86 per 100000 vs 15 per 100000 ), but returned to the rates before $9 / 11$ within 4 years..$^{15}$ Izbicki and co-workers ${ }^{15}$ reported 26 cases of this sarcoid-like disorder in firefighters during the 5 years after 9/11; many had asthma-like symptoms and airway hyper-reactivity not seen in sarcoidosis in NYC firefighters before $9 / 11$. The investigators noted that respiratory symptoms and sarcoid-like granulomatous pulmonary disease might be manifestations of one disease or alternatively could be coexisting disorders. A study of 19756 WTC workers in another cohort ${ }^{22}$ showed a peak of ten confirmed sarcoid-like cases 2 years after $9 / 11$ (an estimated yearly incidence of 54 per 100000)-an increase compared with before $9 / 11$, although data are scarce. However, rates are difficult to calculate because the denominator (the total number of responders) is uncertain..$^{23,33}$ Furthermore, sarcoidosis is often asymptomatic, and more cases might have been detected as a result of increased chest radiographic screening in health monitoring programmes after $9 / 11$.

\section{Birth outcomes}

Proximity to the WTC site on or after $9 / 11$ does not seem to have increased the risk for low birthweight $(<2500 \mathrm{~g})$ or preterm deliveries, ${ }^{34,81,82}$ although Lederman and colleagues $^{82}$ noted a mean decrease in birthweight of $149 \mathrm{~g}$ for babies born to 300 mothers living within 2 miles of the site. Berkowitz and co-workers ${ }^{81}$ recorded a significant risk ratio of 1.9 of intrauterine growth restriction in pregnant women in lower Manhattan on $9 / 11$ or in the 3 weeks after $(n=187)$ than in women about 5 miles from the site $(n=2367)$, after adjustment for race or ethnic origin, infant sex, maternal age, parity, and smoking status. ${ }^{81}$ Maternal stress and probable PTSD related to $9 / 11$ might have been risk factors for adverse birth outcomes. ${ }^{34,83-85}$

Two studies of women in New York City showed that those in their first trimester on $9 / 11$ were more likely to have a shorter gestational duration than were those in their second or third trimester, irrespective of where they lived..$^{34,82}$ A similar effect was reported during the same period in 2000, a year before the attack, which suggests that season might have affected length of pregnancy. ${ }^{34}$

Researchers who examined umbilical cord blood samples did not find clear associations between 9/11 exposures and birth outcomes or child neurodevelopmental effects. ${ }^{86-88}$

\section{Comorbidity}

Two studies ${ }^{27,89}$ have described coexisting mood and anxiety disorders in exposed individuals. In enrollees in the WTC Health Registry who screened positive for chronic PTSD symptoms after the disaster, a third also reported a diagnosis of depression since 9/11.27 Responders with probable PTSD had 13.9 times higher odds for probable depression and 9.2 times higher odds of panic disorder than those without PTSD; comorbid responders were 40-86 times more likely to have emotional disruption of function according to the Sheehan disability scale than were those without PTSD, panic disorder, or depression. ${ }^{16}$

The burden of co-occurring physical and mental illness in individuals directly exposed to the $9 / 11$ attacks was likely to be high because of the concurrent environmental and psychologically traumatising exposures. Few studies have examined both issues, although one report from the WTC Health Registry ${ }^{27}$ suggested substantial comorbid respiratory illness and PTSD: $36 \%$ of 3800 adults who reported asthma diagnosed after $9 / 11$ had probable PTSD in a 2006-07 survey.

\section{Possible late-emerging disorders}

Late-emerging health disorders (such as cancers, which have long latency periods) and premature deaths that might be associated with exposure to the attacks are being studied. The dust and debris contained known carcinogens; thus clinicians and researchers will need to continue to monitor exposed individuals. One case series has been published on multiple myeloma, ${ }^{24}$ but no population studies on 9/11 exposure and cancer outcomes or mortality have been reported at the time of this Review.

\section{Conclusion}

10 years after 9/11, short-term and medium-term health outcomes are generally consistent across studies for the main mental and physical health conditions. The prevalences of PTSD and respiratory illness, including irreversible loss of pulmonary function, were substantial and were strongly associated with direct exposure to the $9 / 11$ attacks in adults. The links between direct exposure to the attacks and several other disorders, such as depression, anxiety, substance use, GERS, and sarcoidosis, need further study. 
Investigations into the health effects of the $9 / 11$ attacks have unique strengths, including the presence of several large cohorts that have been followed up prospectively. For example, a unique longitudinal large-scale assessment of respiratory function was possible in firefightersa group that was directly exposed to the dust cloud and debris after the attacks. Loss to follow-up will be a challenge for many of the large cohorts being followed, and efforts to minimise this loss will be crucial to ensure the validity of future findings.

The 9/11 attacks were unprecedented in many ways (eg, the demands that they placed on the community of investigators studying their health effects) and limitations of the available work mainly arise from the novelty of work done. Studies are limited by the absence of quantitative methods to measure exposure, challenges in estimation of relevant denominators (ie, the size and composition of populations affected by the disaster), and frequent reliance on self-report of symptoms and diagnosed health disorders. Most investigations started data collection months or years after the disaster, which possibly introduced error attributable to recall bias. Furthermore, systematic data collection for population studies started after $9 / 11$ for all groups apart from New York City firefighters, resulting in little information about associated factors relevant before 9/11. Pre-9/11 occupational hazards, trauma, or psychopathology could have been important drivers of the pathological changes documented in the aftermath of the attacks.

Despite much work into the health effects related to the $9 / 11$ attacks, several gaps remain. A few studies have been done for anosmia, ${ }^{90,91}$ sleep apnoea, ${ }^{92,93}$ and cardiac disease, ${ }^{94-96}$ but more research is needed. Additional investigation is needed to examine comorbidity, including interaction of co-occurring mental and physical health problems, and multiple mental health disorders. More studies are needed on associated factors for comorbid mental health conditions, and how this comorbidity affects quality of life, disability, and risk for increased substance use. Treatment of disorders related to the disaster should be assessed, particularly treatment effectiveness for both physical and mental health conditions, and best practices. Information is scarce about who accessed treatment services, how to reach those still in need, and the burden of 9/11-related illness on the local and national health-care systems.

Published reports of the health effects of the 9/11 attacks provide several lessons for research into future disasters. Accurate and replicable assessments of exposures are highly desirable after such events. These assessments are relevant to studies of both mental and physical health. Most epidemiological studies so far have relied on qualitative or semiquantitative exposure assignments derived almost entirely from questionnaires completed by the study participants themselves. Ideally, standardised data collection methods should be used to measure exposures from the onset of an environmental disaster, and rigorous tracking of workers' and volunteers' shifts would improve estimates of both the total exposed population and their extent of exposure. Additionally, recall bias might be minimised by rapid identification and assessment of either the entire exposed group or a representative sample. This fast identification has been possible after other disasters, particularly after the 1995 bombing of the Murrah Building in Oklahoma, ${ }^{97}$ but was infeasible in view of the scale of the $9 / 11$ attacks and because of the many different groups of investigators studying their effects. Furthermore, systematic collection of information about pre-existing physical and mental health conditions and on previous traumatic exposures would help to assess whether new or worsening post-disaster health effects are attributable to a specific event.

Research into 9/11 also provides insight into future disaster response efforts. Interventions that might reduce physical and mental health effects in the short and medium terms after disasters are immediate outreach, screening, and treatment of high-risk populations with targeted, exposure-specific interventions to prevent longterm mental health sequelae; early and consistent use of appropriate respirators when environmental hazards cannot be controlled; and disaster preparedness training and shift rotations to enable shorter work duration of rescue workers.

Finally, lessons from existing research can provide guidance for future studies of illness related to $9 / 11$. First, in view of the challenges in the identification of appropriate, unexposed external comparison populations for the unique cohorts studied after exposure, internal comparisons are often useful. Many of the $9 / 11$ investigations have shown dose-response relations with use of internal comparison groups, with increased exposure associated with a greater likelihood of adverse health effects. Second, as researchers investigate lateemerging and rare disorders, consistency of findings across studies becomes even more important in assessment of associations between exposures related to $9 / 11$ and health outcomes, even when different methods are used. Third, more information is needed to explain the pathophysiology of WTC-related illnesses. Fourth, validation studies such as pulmonary function testing and medical record reviews can help to support self-reported symptoms and diagnoses, and to provide objective measures of the progression of health disorders over time. The continued follow-up of exposed adults and children is needed to document the trajectory of illness, and to detect the onset of illnesses related to $9 / 11$ of longer latency.

\section{Contributors}

CMG, SEP, and JH developed the framework for this Review. JH did the review of published work with input from SEP. All authors were involved in writing and editing the paper, with SEP leading this effort. 


\section{Conflicts of interest}

We declare that we have no conflicts of interest.

\section{Acknowledgments}

We thank Thomas Farley, James Hadler, Adam Karpati, and

Katherine Wheeler for their thoughtful comments on this Review, and Margaret Millstone and Rhoda Schlamm for assistance with preparation of the report. This work was supported by the National Institute for Occupational Safety and Health (Cooperative Agreement 1U50/OH009739), the New York City Department of Health and Mental Hygiene, and Columbia University. The New York City Department of Health and Mental Hygiene participated in the design, development, and review of the Review.

\section{References}

1 Farfel M, DiGrande L, Brackbill R, et al. An overview of 9/11 experiences and respiratory and mental health conditions among World Trade Center Health Registry enrollees. J Urban Health 2008; 85: 880-909.

2 Lorber M, Gibb H, Grant L, Pinto J, Pleil J, Cleverly D. Assessment of inhalation exposures and potential health risks to the general population that resulted from the collapse of the World Trade Center towers. Risk Anal 2007; 27: 1203-21.

3 Lowers HA, Meeker GP, Lioy PJ, Lippmann M. Summary of the development of a signature for detection of residual dust from collapse of the World Trade Center buildings.

J Expo Sci Environ Epidemiol 2009; 19: 325-35.

4 Centers for Disease Control and Prevention. Occupational exposures to air contaminants at the World Trade Center disaster site-New York, September-October, 2001. MMWR Morb Mortal Wkly Rep 2002; 51: 453-56.

5 Geyh AS, Chillrud S, Williams DL, et al. Assessing truck driver exposure at the World Trade Center disaster site: personal and area monitoring for particulate matter and volatile organic compounds during October 2001 and April 2002. J Occup Environ Hyg 2005; 2: 179-93.

6 Landrigan PJ, Lioy PJ, Thurston G, et al. Health and environmental consequences of the World Trade Center disaster. Environ Health Perspect 2004; 112: 731-39.

7 McGee JK, Chen LC, Cohen MD, et al. Chemical analysis of World Trade Center fine particulate matter for use in toxicological assessment. Environ Health Perspect 2003; 111: 972-80.

8 Berninger A, Webber MP, Niles JK, et al. Longitudinal study of probable post-traumatic stress disorder in firefighters exposed to the World Trade Center disaster. Am J Ind Med 2010; 53: $1177-85$.

9 Banauch B, Hall C, Weiden M, et al. Pulmonary function after exposure to the World Trade Center collapse in the New York City Fire Department. Am J Respir Crit Care Med 2006; 174: 312-19.

10 Webber MP, Gustave J, Lee R, et al. Trends in respiratory symptoms of firefighters exposed to the World Trade Center disaster: 2001-2005. Environ Health Perspect 2009; 117: 975-80.

11 Prezant D, Weiden M, Banauch GI, et al. Cough and bronchial responsiveness in firefighters at the World Trade Center site. N Engl J Med 2002; 347: 806-15.

12 Aldrich TK, Gastave J, Hall CB, et al. Lung function in rescue workers at the World Trade Center after 7 years. N Engl J Med 2010; 362: 1263-72.

13 Weiden MD, Ferrier N, Nolan A, et al. Obstructive airways disease with air trapping among firefighters exposed to World Trade Center dust. Chest 2010; 137: 566-74.

14 Rom WN, Weiden M, Garcia R, et al. Acute eosinophilic pneumonia in a New York City firefighter exposed to World Trade Center dust. Am J Respir Crit Care Med 2002; 166: 797-800.

15 Izbicki G, Chavko R, Banauch GI, et al. World Trade Center "sarcoid-like" granulomatous pulmonary disease in New York City Fire Department rescue workers. Chest 2007; 131: 1414-23.

16 Stellman J, Smith R, Katz C, et al. Enduring mental health morbidity and social function impairment in World Trade Center rescue, recovery and cleanup workers: the psychological dimension of an environmental health disaster. Environ Health Perspect 2008; 116: $1248-53$.

17 Katz C, Levin S, Herbert R, Munro S, Pandya A, Smith R. Psychiatric symptoms in Ground Zero ironworkers in the aftermath of 9/11: prevalence and predictors. Psychiatr Bull 2009; 131: 49-52.
18 Herbert R, Moline J, Skloot GS, et al. The World Trade Center disaster and the health of workers: five-year assessment of a unique medical screening program. Environ Health Perspect 2006; 114: 1853-58.

19 Skloot GS, Schechter CB, Herbert R, et al. Longitudinal assessment of spirometry in the World Trade Center medical monitoring program. Chest 2009; 135: 492-98.

20 de la Hoz RE, Shohet MR, Chasan R, et al. Occupational toxicant inhalation injury: the World Trade Center experience. Int Arch Occup Environ Health 2008; 81: 479-85.

21 de la Hoz RE, Christie J, Teamer JA, et al. Reflux symptoms and disorders and pulmonary disease in former World Trade Center rescue and recovery workers and volunteers. J Occup Environ Med 2008; 50: 1351-54.

22 Crowley LE, Herbert R, Moline JM, et al. "Sarcoid like” granulomatous pulmonary disease in World Trade Center disaster responders. Am J Ind Med 2010; 54: 175-84.

23 Savitz DA, Oxman RT, Metzger KB, et al. Epidemiologic research on man-made disasters: strategies and implications of cohort definition for World Trade Center worker and volunteer surveillance program. Mt Sinai J Med 2008; 75: 77-87.

24 Moline MS, Herbert RH, Crowley L, et al. Multiple myeloma in World Trade Center responders: a case series. J Occup Environ Med 2009; 51: 1-7.

25 Lin S, Jones R, Reibman J, Bowers J, Fitzgerald EF, Hwang SA Reported respiratory symptoms and adverse home conditions after 9/11 among residents living near the World Trade Center. J Asthma 2007; 44: 325-32.

26 Reibman J, Liu M, Chen Q, et al. Characteristics of a residential and working community with diverse exposure to World Trade Center dust, gas, and fumes. J Occup Environ Med 2009; 51: 534-41.

27 Brackbill RM, Hadler JL, DiGrande L, et al. Asthma and posttraumatic stress symptoms 5 to 6 years following exposure to the World Trade Center terrorist attack. JAMA 2009; 302: 502-16.

28 Perrin M, DiGrande L, Wheeler K, et al. Differences in PTSD prevalence and associated risk factors among World Trade Center Disaster rescue and recovery workers. Am J Psychiatry 2007; 164: 1385-94.

29 DiGrande L, Neria Y, Brackbill RM, Pulliam P, Galea S. Long-term posttraumatic stress symptoms among 3,271 civilian survivors of the September 11, 2001 terrorist attacks on the World Trade Center. Am J Epidemiol 2011; 173: 271-81.

30 Murphy J. Measuring and maximizing coverage in the World Trade Center Health Registry. Stat Med 2007; 26: 1688-701.

31 Wheeler K, McKelvey W, Thorpe L, et al. Asthma diagnosed after September 112001 among rescue and recovery workers: findings from the World Trade Center Health Registry. Environ Health Perspect 2007; 115: 1584-90.

32 Thomas PA, Brackbill R, Thalji L, et al. Respiratory and other health effects reported in children exposed to the World Trade Center disaster of September 11, 2001. Environ Health Perspect 2008; 116: 1383-90.

33 Brackbill RM, Thorpe LE, DiGrande L, et al. Surveillance for World Trade Center disaster health effects among survivors of collapsed and damaged buildings. MMWR Surveill Summ 2006; 55: 1-18.

34 Lipkind HS, Curry AE, Huynh M, Thorpe LE, Matte T. Birth outcomes among offspring of women exposed to the September 11, 2001, terrorist attacks. Obstet Gynecol 2010; 116: 917-25.

35 Centers for Disease Control and Prevention. World Trade Center Health Program: number of participants in the WTC Health Programs. March 31, 2011. http://www.cdc.gov/niosh/topics/wtc/ census.html (accessed May 26, 2011).

36 World Trade Center Medical Working Group of New York City. 2009 annual report on 9/11 health. September 2009. http://www.nyc. gov/html/doh/wtc/downloads/pdf/news/2009_mwg_annual_ report.pdf (accessed May 26, 2011).

37 Blanchard EB, Jones-Alexander J, Buckley TC, Forneris CA. Psychometric properties of the PTSD checklist (PCL). Behav Res Ther 1996; 34: 669-73.

38 Schuster M, Stein BD, Jaycox L, et al. A national survey of stress reactions after the September 11, 2001, terrorist attacks. N Engl J Med 2001; 345: 1507-12.

39 Silver RC, Holman EA, McIntosh DN, Poulin M, Gil-Rivas V. Nationwide longitudinal study of psychological responses to September 11. JAMA 2002; 288: 1235-44. 
40 Schlenger WE, Caddell JM, Ebert L, et al. Psychological reactions to terrorist attacks: findings from the National Study of Americans' Reactions to September 11. JAMA 2002; 288: 581-88.

41 Galea S, Resnick H. Posttraumatic stress disorder in the general population after mass terrorist incidents: considerations about the nature of exposure. CNS Spectr 2005; 10: 107-15.

42 Cohen P, Kasen S, Chen H, et al. Current affairs and the public psyche: American anxiety in the post 9/11 world. Soc Psychiatry Psychiatr Epidemiol 2006; 41: 251-60.

43 Cardeña E, Dennis JM, Winkel M, Skitka LJ. A snapshot of terror: acute posttraumatic responses to the September 11 attack. J Trauma Dissociation 2005; 6: 69-84.

44 Breslau N, Bohnert KM, Koenen KC. The 9/11 terrorist attack and posttraumatic stress disorder revisited. J Nerv Ment Dis 2010; 198: 539-43.

45 Galea S, Ahern J, Resnick H, et al. Psychological sequelae of the September 11 terrorist attacks in New York City. N Engl J Med 2002; 346: 982-87.

46 Galea S, Vlahov D, Resnick H, et al. Trends of probable post-traumatic stress disorder in New York City after the September 11 terrorist attacks. Am J Epidemiol 2003; 158: 514-24.

47 Nandi A, Galea S, Tracy M, et al. Job loss, unemployment, work stress, job satisfaction, and the persistence of posttraumatic stress disorder one year after the September 11 attacks. J Occup Environ Med 2004; 46: 1057-64.

48 New York City Health Department. WTC Health Registry. 2011. http://www.nyc.gov/html/doh/wtc/html/registry/registry.shtml (accessed Aug 4, 2011).

49 Evans S, Patt I, Giosan G, Spielman L, Difede J. Disabilty and posttraumatic stress disorder in disaster relief workers responding to September 11, 2001 World Trade Center disaster. J Clin Psychol 2009; 65: 684-94.

50 Brewin CR. Systematic review of screening instruments for adults at risk of PTSD. J Trauma Stress 2005; 18: 53-62.

51 North CS, Pfefferbaum B, Narayanan P, et al. Comparison of post-disaster psychiatric disorders after terrorist bombings in Nairobi and Oklahoma City. Br J Psychiatry 2005; 186: 487-93.

52 Vlahov D, Galea S, Resnick H, et al. Increased use of cigarettes, alcohol and marijuana among Manhattan, New York, residents after the September 11th terrorist attacks. Am J Epidemiol 2002; 155: 988-96.

53 Wu P, Duarte CS, Mandell DJ, et al. Exposure to the World Trade Center attack and the use of cigarettes and alcohol among New York City public high-school students. Am J Public Health 2006 96: 804-07.

54 Boscarino JA, Adams RE, Galea S. Alcohol use in New York after the terrorist attacks: a study of the effects of psychological trauma on drinking behavior. Addict Behav 2006; 31: 606-21.

55 Vlahov D, Galea S, Ahern J, et al. Consumption of cigarettes, alcohol and marijuana among New York City residents six month after the September 11th terrorist attacks. Am J Drug Alcohol Abuse 2004; 30: 385-407.

56 Chemtob C, Nomura Y, Josephson L, Adams RE, Sederer L. Substance use and functional impairment among adolescents directly exposed to the 2001 World Trade Center attacks. Disasters 2009; 33: 337-52.

57 Mezuk B, Larkin GL, Prescott MR, et al. The influence of a major disaster on suicide risk in the population. J Trauma Stress 2009; 22: 481-88.

58 Pridemore WA, Trahan A, Chamlin MB. No evidence of suicide increase following terrorist attacks in the United States: an interrupted time-series analysis of September 11 and Oklahoma City. Suicide Life Threat Behav 2009; 39: 659-70.

59 Claassen CA, Carmody T, Stewart SM, et al. Effect of 11 September 2001 terrorist attacks in the USA on suicide in areas surrounding the crash sites. Br J Psychiatry 2010; 196: 359-64.

60 Salib E. Effect of 11 September 2001 on suicide and homicide in England and Wales. Br J Psychiatry 2003; 183: 207-12.

61 Hoven CW, Duarte CS, Lucas CP, et al. Psychopathology among New York City public school children 6 months after September 11. Arch Gen Psychiatry 2005; 62: 545-52.

62 Fairbrother G, Stuber J, Galea S, Fleischman AR, Pfefferbaum B. Posttraumatic stress reactions in New York City children after the September 11, 2001, terrorist attacks. Ambul Pediatr 2003; 3: 304-11.
63 Pfefferbaum B, Stuber J, Galea S, Fairbrother G. Panic reactions to terrorist attacks and probable posttraumatic stress disorder in adolescents. J Trauma Stress 2006; 19: 217-28.

64 Chemtob CM, Nomura Y, Abramovitz RA. Impact of conjoined exposure to the World Trade Center attacks and to other traumatic events on the behavioral problems of preschool children. Arch Pediatr Adolesc Med 2008; 162: 126-33.

65 Herbstman JB, Frank R, Schwab M, et al. Respiratory effects of inhalation exposure among workers during the clean-up effort at the World Trade Center disaster site. Environ Res 2005; 99: 85-92.

66 Mauer MP, Herdt-Losavio ML, Carlson GA. Asthma and lower respiratory symptoms in New York State employees who responded to the World Trade Center disaster. Int Arch Occup Environ Health 2010; 83: 21-27.

67 Mauer MP, Cummings KR, Hoen R. Long-term respiratory symptoms in World Trade Center responders. Occup Med (Lond) 2010; 60: 145-51.

68 Salzman SH, Moosavy FM, Miskoff JA, Friedmann P, Rosen MJ. Early respiratory abnormalities in emergency services police officers at the World Trade Center site. J Occup Environ Med 2004 46: $113-22$

69 Safirstein BH, Klukowicz A, Miller R, Teirstein A. Granulomatous pneumonitis following exposure to the World Trade Center collapse. Chest 2003; 123: 301-04.

70 Mann JM, Sha KK, Breuer FU, Miller A. World Trade Center dyspnea: bronchiolitis obliterans with functional improvement: a case report. Am J Ind Med 2005; 48: 225-29.

71 Mendelson DS, Roggeveen M, Levin SM, et al. Air trapping detected on end-expiratory high-resolution computed tomography in symptomatic World Trade Center rescue and recovery workers. J Occup Environ Med 2007; 49: 840-45.

72 Oppenheimer BW, Goldring RM, Herberg ME, et al. Distal airway function in symptomatic subjects with normal spirometry following World Trade Center dust exposure. Chest 2007; 132: 1275-82.

73 Szema AM, Khedkar M, Maloney PF, et al. Clinical deterioration in pediatric asthmatic patients after September 11, 2001. J Allergy Clin Immunol 2004; 113: 420-26.

74 Centers for Disease Control and Prevention. Lifetime asthm prevalence percents by age, United States: National Health Interview Survey, 2003. 2003. http://www.cdc.gov/asthma/nhis/03/ table2-1.htm (accessed Aug 5, 2011).

75 Centers for Disease Control and Prevention. Rapid assessment of injuries among survivors of the terrorist attack on the World Trade Center-New York City, September 2001. MMWR Morb Mortal Wkly Rep 2002; 51: 1-5.

76 Locke GR 3rd, Talley NJ, Fett SL, Zinsmeister AR, Melton LJ 3rd. Prevalence and clinical spectrum of gastroesophageal reflux: a population-based study in Olmsted County, Minnesota. Gastroenterology 1997; 112: 1448-56

77 Havemann BD, Henderson CA, El-Serag HB. The association between gastro-oesophageal reflux disease and asthma: a systematic review. Gut 2007; 56: 1654-64

78 Ruigomez A, Rodriguez LA, Wallander MA, Johansson S, Thomas M, Price D. Gastroesophageal reflux disease and asthma: a longitudinal study in UK general practice. Chest 2005; 128: 85-93.

79 Mizyed I, Fass SS, Fass R. Review article: gastro-oesophageal reflux disease and psychological comorbidity. Aliment Pharmacol Ther 2009; 29: 351-58.

80 Mayer EA. The neurobiology of stress and gastrointestinal disease Gut 2000; 47: 861-69.

81 Berkowitz GS, Wolff MS, Janevic TM, Holzman IR, Yehuda R, Landrigan PR. The World Trade Center disaster and intrauterine growth restriction. JAMA 2003; 290: 595-96.

82 Lederman SA, Rauh V, Weiss L, et al. The effects of the World Trade Center event on birth outcomes among term deliveries at three lower Manhattan hospitals. Environ Health Perspect 2004; 112: 1772-78.

83 Yehuda R, Engel SM, Brand SR, Secki J, Marcus SM, Berkowitz GS Transgenerational effects of posttraumatic stress disorder on babies of mothers exposed to the World Trade Center attacks during pregnancy. J Clin Endocrinol Metab 2005; 90: 4115-18.

84 Eskenazi B, Marks AR, Catalano R, Bruckner T, Toniolo PG. Low birthweight in New York City and upstate New York following the events of September 11th. Hum Reprod 2007; 22: 3013-20. 
85 Engel S, Berkowitz GS, Wolff MS, Yehuda R. Psychological trauma associated with the World Trade Center attacks and its effect on pregnancy outcome. Paediatr Perinat Epidemiol 2005; 19: 334-41.

86 Herbstman JB, Sjodin A, Kurzon M, et al. Prenatal exposure to PBDEs and neurodevelopment. Environ Health Perspect 2010; 118: 712-19.

87 Lederman SA, Jones RL, Caldwell KL, et al. Relation between cord blood mercury levels and early child development in a World Trade Center cohort. Environ Health Perspect 2008; 116: 1085-91.

88 Perera FP, Tang D, Rauh V, et al. Relationship between polycyclic aromatic hydrocarbon-DNA adducts, environmental tobacco smoke and child development in the World Trade Center cohort. Environ Health Perspect 2007; 115: 1497-1502.

89 Henriksen CA, Bolton JM, Sareen J. The psychological impact of terrorist attacks: examining a dose-response relationship between exposure to 9/11 and Axis I mental disorders. Depress Anxiety 2010; 27: 993-1000.

90 Dalton PH, Opiekum RE, Gould M, et al. Chemosensory loss: functional consequences of the World Trade Center disaster. Environ Health Perspect 2010; 118: 1251-56.

91 Altman K, Desai S, Moline J, et al. Odor identification ability and self-reported upper respiratory symptoms in workers at the post-9/11 World Trade Center site. Int Arch Occup Environ Health 2011; 84: 131-37.
92 Webber MP, Lee R, Soo J, et al. Prevalence and incidence of high risk for obstructive sleep apnea in World Trade Center-exposed rescue/recovery workers. Sleep Breath 2010; published online July 1. DOI:10.1007/s11325-010-0379-7.

93 de la Hoz RE, Aurora RN, Landsbergis P, Bienenfeld LA, Afilaka AA, Herbert R. Snoring and obstructive sleep apnea among former World Trade Center rescue workers and volunteers. J Occup Environ Med 2010; 52: 29-32.

94 Holman EA, Silver RC, Poulin M, Andersen J, Gil-Rivas V, McIntosh DN. Terrorism, acute stress, and cardiovascular health: a 3-year national study following the September 11th attacks. Arch Gen Psychiatry 2008; 65: 73-80.

95 Steinberg JS, Arshad A, Kowalski M. Increased incidence of life-threatening ventricular arrhythmias in implantable defibrillator patients after the World Trade Center attack. J Am Coll Cardiol 2004; 44: 1261-64.

96 Lin S, Gomez MI, Gensburg L, Liu W, Hwang SA. Respiratory and cardiovascular hospitalizations after the World Trade Center disaster. Arch Environ Occup Health 2010; 65: 12-20.

97 Mallonee S, Shariat S, Stennies G, Waxweiler R, Hogan D, Jordan F. Physical injuries and fatalities resulting from the Oklahoma City bombing. JAMA 1996; 276: 382-87. 